\title{
ACESSO À JUSTIÇA POPULAR: UMA IMPORTANTE EXPERIÊNCIA PRÁTICO- JURÍDICA-SOCIAL UNIVERSITÁRIA
}

\author{
Idir Canzi \\ Universidade Comunitária da Região de Chapecó - UNOCHAPECÓ \\ canzi@unochapeco.edu.br \\ Deisemara Turatti Langoski \\ Universidade Comunitária da Região de Chapecó - UNOCHAPECÓ \\ deisetl@unochapeco.edu.br \\ Geslene Agostini \\ Universidade Comunitária da Região de Chapecó - UNOCHAPECÓ \\ giagostini@yahoo.com.br
}

\section{Resumo}

O presente artigo centra o desenvolvimento de seu conteúdo na temática do acesso à justiça popular. Contextualiza primeiramente o acesso à Justiça Popular e o seu alcance no Brasil. Descreve as importantes contribuições da atuação do ESJ - Escritório Sócio-Jurídico da Unochapecó - Universidade Comunitária da Região de Chapecó - SC, enquanto instrumento de acesso à Justiça popular na Comarca de Xaxim - SC. Apresenta e analisa o rol de atendimentos e ações ajuizadas pelo ESJ em favor da população usuária dos serviços da Assistência jurídica integral e gratuita (artigo $5^{\circ}$, inciso LXXIV da Constituição Federal de 1988 e Lei 1060/50), a partir da execução de estruturada pesquisa documental, nas competências 2003 a 2011. Ainda, insere a análise dos resultados das decisões judiciais dos processos ajuizados pelo Escritório Sócio-Jurídico da Unochapecó nas competências anunciadas. Finaliza atestando que o Escritório Sócio-Jurídico da Unochapecó na Comarca de Xaxim, SC, contribui de forma efetiva para que a população usuária tenha respeitado o acesso à justiça e ao sistema judiciário, por meio do oferecimento qualificado de serviços sóciojurídicos, com atuação de profissionais e estudantes em estágio curricular que acompanham administrativa e judicialmente a integralidade das demandas.

Palavras-chave: Acesso à Justiça popular. Escritório Sócio-Jurídico da Unochapecó. Assistência jurídica integral e gratuita. 


\title{
ACCESS TO POPULAR JUSTICE: AN IMPORTANT PRACTICAL -LEGAL- SOCIAL COLLEGE EXPERIENCE
}

\begin{abstract}
This article focuses the development of its content in the theme of access to popular justice. It contextualizes firstly the access to Popular Justice and its reach in Brazil. It describes the important contributions of the performance of the ESJ - Socio-Legal Department of Unochapecó - Community University of Chapecó - SC, as a tool of access to Popular Justice in the Judicial District of Xaxim - SC. It presents and analyzes the number of attendances and lawsuits by ESJ in favor of the service users of the full and free legal assistance (Article $5^{\circ}$, item LXXIV of the Federal Constitution of 1988 and Law 1060/50), from the implementation of structured documentary research, from 2003 to 2011. It also includes the analysis of the results of judgments from lawsuits brought by the Socio-Legal Office of Unochapecó, in the competences announced. It concludes by stating that the Socio-Legal Office of Unochapecó in the Judicial District of Xaxim, SC, has effectively contributed for the users to have guaranteed the access to justice and the judicial system, through qualified socio-legal services, with operations of professionals and students in curricular internship who accompany administratively and judicially the demands integrity.
\end{abstract}

Keywords: Access to Popular Justice. Socio-Legal Department of Unochapecó. Full and free legal assistance. 


\section{INTRODUÇÃO}

O exercício da cidadania e dos direitos constitui-se na possibilidade de acesso à justiça, considerados os mais elementares dos direitos humanos. $\mathrm{O}$ acesso à justiça não é apenas um direito social reconhecido e assegurado constitucionalmente, deve ser efetivo e propiciar a acessibilidade da ordem jurídica justa para toda a população. Na sociedade que se pretende justa e igual, as pessoas devem exercer plenamente seus direitos e deveres: ser sujeitos de direito.

A Unochapecó, enquanto universidade comunitária oferece espaços para as práticas jurídico-sociais, dentre estas, destaca-se o Escritório Sócio-Jurídico, que atua como estágio, promovendo o acesso a direitos e à justiça para a população hipossuficiente.

Este artigo tem por intuito analisar as contribuições da atuação do Escritório SócioJurídico da Unochapecó, notadamente no que diz respeito ao acesso à justiça para a população usuária, a partir da competência 2003.

\section{Contextualizando o acesso à justiça popular}

A Constituição Federal de 1988, em seu artigo 5, XXXV, estabelece: “A lei não excluirá da apreciação do Poder Judiciário lesão ou ameaça a direito". Referido dispositivo constitucional formaliza o princípio do acesso aos tribunais e do direito de ação, consistindo, por consequência no princípio do acesso à justiça.

$\mathrm{O}$ acesso à justiça na contemporaneidade é encarado como um requisito fundamental à cidadania, o mais básico dos direitos humanos, de um sistema jurídico atual e igualitário, que pretende garantir e não apenas proclamar os direitos de todos.

Ao tempo em que as sociedades evoluíram e se transformaram, houve a necessidade do surgimento do Estado para instituir formas de controle, criação de normas, de regramento de poder e também a instituição de meios para ter acesso à entidade estatal, afim de que a sociedade possa concretizar os seus anseios de acesso à justiça com efetividade.

Os cidadãos necessitam de regras públicas para exercerem sua autonomia, pois além de serem os sujeitos dos direitos previstos na Constituição, são os protagonistas dos direitos que dignifiquem, valorizem a pessoa humana nos espaços públicos e na sociedade. Ser cidadão pressupõe estar informado, desperto e consciente sobre o valor da pessoa humana, a 
necessidade de conviver e respeitar a dignidade de todos os seres humanos, independentemente das diferenças sociais, econômicas, pessoais (DALLARI, 2004).

Para (BRANDÃO, 2012, p. 05) “A democracia só se concretiza através da participação efetiva do cidadão, sendo alcançada apenas através do acesso à justiça de forma indiscriminada." Sob este enfoque, o acesso a uma ordem jurídica justa, que restabeleça os direitos fundamentais do cidadão, deve fundar-se na valorização do ser humano, na dignidade da pessoa humana, consciente da possibilidade do pleno exercício dos direitos e garantias inerentes ao cidadão (CAOVILLA, 2006).

$\mathrm{O}$ conceito de acesso à justiça tem sofrido uma transformação importante, correspondente a uma mudança processual, com o aparecimento de novos mecanismos de acessar a justiça. A teoria era de que, embora o acesso à justiça pudesse ser um "direito natural", os direitos naturais não necessitavam de uma ação do Estado para sua proteção. Esses direitos eram considerados anteriores ao Estado; sua preservação exigia apenas que o Estado não permitisse que eles fossem infringidos por outros. De fato, o direito ao acesso efetivo tem sido progressivamente reconhecido como sendo de importância capital entre os novos direitos individuais e sociais, uma vez que a titularidade de direitos é destituída de sentido, na ausência de mecanismos para sua efetiva reivindicação (CAPELETTI, 1988).

De longa data, a sociedade tem demonstrado o seu descontentamento com a atividade jurisdicional, caracterizada pela morosidade, inadequação da organização judiciária, deficiência da assistência judiciária gratuita (a exemplo de Santa Catarina que somente em 18 de julho de 2012 aprovou a criação da Defensoria Pública). Por estes motivos, constata-se a necessidade de acessibilidade efetiva dos cidadãos à Justiça, entre estes, destaca-se as pessoas hipossuficientes economicamente, pelo fato de não vislumbrarem formas de superar as barreiras existentes para alcançar o acesso à Justiça, esta "desigualdade sócio-financeira tem como resultado uma desigualdade processual” (BRANDÃO, 2012, p.05).

Neste sentido, o acesso à justiça deve propiciar não apenas a submissão dos conflitos e problemas das pessoas à estrutura do poder judiciário, mas garantir e assegurar que todos os cidadãos conheçam seus direitos, que sejam assegurados pelo ente estatal e ainda por estes informados no caso de desconhecimento, especialmente àquela parcela da população que vive na miserabilidade financeira, como forma de garantir a igualdade de condições no âmbito do processo. 
Reconhece Greco (apud BRANDÃO, 2012, p. 07) que "O Acesso à Justiça não estará concretamente assegurado se o Estado não oferecer a todos a possibilidade de receber aconselhamento jurídico a respeito de seus direitos".

\section{Caracterização do Escritório Sócio-Jurídico da Unochapecó}

O Escritório Sócio Jurídico - ESJ, projeto permanente de extensão universitária foi criado em 1992, substituindo o Escritório Modelo de Advocacia, constituído em 1988, e, tem como objetivo oferecer estágio curricular aos estudantes dos cursos de Direito, Psicologia e Serviço Social da Unochapecó, na busca de aproximar o estudante da realidade profissional, possibilitando formação crítica, ética e comprometida com as demandas sociais.

$\mathrm{O}$ atendimento se estende às pessoas que se enquadram nos critérios da Assistência Jurídica Integral e Gratuita, nos termos do artigo $5^{\circ}, \operatorname{LXXIV}^{1}$ da $\mathrm{CF} / 88$ e Lei Federal $n^{\circ}$ 1.060/50, delimitado à população com renda familiar até três salários mínimos. As demandas são oriundas de grupos familiares ou indivíduos em situação de vulnerabilidade que necessitam atendimento no âmbito social, psicológico e jurídico.

O contato dos supervisores e estudantes com o segmento da população atendida no ESJ trouxe à tona a percepção de uma série de problemas sociais que demandavam ações para além da área jurídica. Com a criação do curso de Serviço Social, a realidade que se apresentava, aliada às necessidades e interesses de ambos os cursos, possibilitaram o intercâmbio dos diferentes saberes, culminando com a implantação do projeto Escritório Sócio-jurídico em julho de 1992. Ao longo dos anos de operacionalização dos serviços do ESJ percebeu-se a necessidade de inclusão de outras áreas do conhecimento que ampliasse a possibilidade de atendimento à população. Registra-se, que a partir do $2^{\circ}$ semestre de 1999 , o curso de Psicologia veio a somar e ampliar referido atendimento.

Com o aumento da demanda, vislumbrou-se a necessidade de ampliar o serviço prestado. Neste sentido, a universidade firmou parceria com o Município de Xaxim para a implementação do ESJ, a partir do $2^{\circ}$ semestre de 1999.

O projeto tem como objetivos proporcionar o adequado atendimento a população de baixo ou inexistente poder aquisitivo, nas áreas jurídica, psicológica e social, possibilitando o

1 Art. 50. [...] LXXIV - o Estado prestará assistência jurídica integral e gratuita aos que comprovarem insuficiência de recursos; 
acesso à justiça e, além disto, ofertar um campo de estágio supervisionado aos estudantes dos cursos de Direito, Serviço Social e Psicologia, a partir do atendimento à comunidade, por meio da prática profissional, a articulação do ensino, pesquisa e extensão.

O Escritório Sócio-Jurídico, desde sua implantação, devido a inércia do poder estatal catarinense em implantar a Defensoria Pública, passou a ser o local onde a população economicamente carente encontra espaço para resolver seus problemas na área jurídica, instrumentalizando os meios de acesso à justiça.

\section{Do alcance do acesso à justiça}

Na Constituição Federal de 1988, em seu Preâmbulo², os representantes do povo, apresentaram os desígnios do seu ofício: instituir um Estado Democrático, assegurando o exercício dos direitos sociais, individuais, além da liberdade, da segurança, do bem-estar, do desenvolvimento, da igualdade e da justiça como valores máximos de uma sociedade fraterna, pluralista e sem preconceitos.

A cidadania se estabelece na forma de preceito fundamental e norteador da própria República, pois além de estatuir-se no seio dos direitos ditos fundamentais, vincula as diretrizes sociais e os objetivos trazidos pela $\mathrm{CF} / 1988$, visando construir uma sociedade livre, justa e solidária, garantindo o desenvolvimento nacional e erradicando a pobreza, a marginalização, enfim, de modo a reduzir as desigualdades sociais e regionais.

A Constituição resgata em seu texto a cidadania, quando se compromete com a convivência social harmônica e prima pela solução pacífica das controvérsias, permitindo, por sua vez, a todos os cidadãos alcançar o acesso à justiça.

Andrigui (1998, p. 2) assevera que o termo Acesso à Justiça, apresenta dois sentidos, a saber: “[...] o primeiro, atribuindo às palavras Justiça e Judiciário o mesmo significado, tornando sinônimas as expressões acesso à justiça e acesso ao judiciário; o segundo atribui à expressão justiça uma visão axiológica que abarca uma determinada ordem de valores e direitos fundamentais para o ser humano".

2 Nós, representantes do povo brasileiro, reunidos em Assembléia Nacional Constituinte para instituir um Estado Democrático, destinado a assegurar o exercício dos direitos sociais e individuais, a liberdade, a segurança, o bem-estar, o desenvolvimento, a igualdade e a justiça como valores supremos de uma sociedade fraterna, pluralista e sem preconceitos, fundada na harmonia social e comprometida, na ordem interna e internacional, com a solução pacífica das controvérsias [...]. 
Nesta pesquisa, toma-se por parâmetro a expressão do acesso à justiça como o ingresso da população ao sistema judiciário para a resolução dos conflitos, notadamente pela população alvo dos atendimentos do Escritório Sócio-Jurídico, que se caracteriza em pessoas consideradas carentes economicamente e também de informações sobre seus direitos e deveres.

A população de baixa renda tem dificuldades de concretizar, na prática, o efetivo acesso à justiça, especialmente quanto ao conhecimento de seus direitos e deveres para a ação cotidiana. A desinformação e a falta de conhecimento privam o cidadão do exercício de seus direitos básicos, como a igualdade, a liberdade, a segurança, a moradia, a educação, direitos estes ligados à dignidade do ser humano.

Assevera Watanabe (1988, p. 128) que “A problemática do acesso à Justiça não pode ser estudada nos acanhados limites do acesso aos órgãos judiciais já existentes. Não se trata apenas de possibilitar o acesso à Justiça enquanto instituição estatal, e sim de viabilizar o acesso à ordem jurídica justa”.

Por conseguinte, o acesso à justiça é mais amplo do que simplesmente o acesso ao Poder Judiciário.

\section{MATERIAL E MÉTODOS}

O objeto de análise consiste em verificar a atuação do ESJ - Escritório Sócio Jurídico da Unochapecó, nos processos ajuizados na Comarca de Xaxim-SC no período de 2003 a 2011, como forma de garantir o acesso à justiça à população hipossuficiente desta comunidade.

\section{O Escritório Sócio-Jurídico da Unochapecó - Campus Xaxim}

O Escritório Sócio-Jurídico da Unochapecó - Campus Xaxim, desde sua criação no ano de 1999, funcionou em espaço cedido pelo Município na Rodoviária. No ano de 2007, em razão do significativo aumento da demanda e da implantação do curso de Direito no Campus, a Unochapecó inaugurou, recentemente (30 de maio de 2012) a nova estrutura física, localizado na Rua Rui Barbosa, no 449, ao lado do Fórum e, atende a população da Comarca de Xaxim³ ${ }^{3}$ com renda familiar até 3 salários mínimos.

3 Fazem parte da Comarca de Xaxim os municípios de Entre Rios, Lageado Grande, Marema e Xaxim. 
Oferecendo à comunidade a prestação de serviços jurídico-sociais, o Escritório Sócio Jurídico - Campus Xaxim (ESJ-Xaxim) está diretamente ligado aos cursos de Direito e Serviço Social da Unochapecó. O atendimento à população é realizado por estudantes em estágio curricular obrigatório, supervisionados pelos professores e atende situações que envolvem as áreas jurídicas de Direito Civil e Processual Civil, Penal e Processual Penal, Trabalho e Previdenciário, além da atuação do curso de Serviço Social junto às Famílias e em situações que envolvam a Seguridade Social.

$\mathrm{Na}$ esfera dos direitos, o Escritório Sócio Jurídico conquistou reconhecimento da comunidade regional pelos serviços prestados e, mantém interlocução com instituições como Conselhos Tutelares, Fórum de Justiça, Conselho Regional de Assistência Social, Municípios da Comarca de Xaxim, OAB, INSS, dentre outras.

Para o Juiz da $1^{\text {a }}$ Vara da Comarca de Xaxim, Dr. Christian Dalla Rosa, a prestação dos serviços sócio-jurídicos que estão disponíveis em Xaxim irá contribuir em muito para reduzir o número de processos da Comarca, que atualmente chegam a mais de 6 mil processos. Ressalta ainda que: "Muitos destes processos são relacionados ao Direito Familiar, e tenho certeza que muitos casos sequer se tornarão ações na Comarca, pois podem ser resolvidos antes que se tornem ações judiciais" (UNOCHAPECÓ, 2012, s.p.).

\section{RESULTADOS E ANÁLISE}

\section{A experiência da atuação do Escritório Sócio-Jurídico de Xaxim na competência 2003 - 2011}

O escritório de prática jurídica do Curso de Direito da Unochapecó - Campus Xaxim - Santa Catarina, denominado Escritório Sócio Jurídico foi estruturado e iniciou suas atividades no ano de 1999, mantém-se em funcionamento até a presente data.

Para o estudo em apreço foi utilizada a pesquisa bibliográfica e documental, cujo objeto de estudo levou em conta $100 \%$ das demandas ajuizadas, a partir da competência $2003^{4}$

4 Nos anos de 1999 a 2002, o ESJ - Xaxim esteve em funcionamento, entretanto para efeito desta pesquisa foram considerados os dados a partir de 2003. Para registro, no ano de 1999, foram efetuados 69 atendimentos; Nos anos de 2000 e 2001 não foram encontrados dados na instituição sobre o número de atendimentos e/ou demandas ajuizadas e, no ano de 2002 foram computados 114 atendimentos, porém, este dado foi buscado junto aos arquivos do curso de Serviço Social, pela falta de informações junto aos documentos no ESJ - Xaxim. No período citado não havia a discriminação nos relatórios institucionais das demandas judiciais, 
Acesso à justiça popular: uma importante experiência prático-jurídica-social universitária

na Comarca de Xaxim, SC. A pesquisa buscou verificar a efetividade, enquanto resultado(s) de decisões favoráveis, em processos ajuizados pelo Escritório Sócio-Jurídico da Unochapecó.

Os relatórios anuais das atividades de extensão da Unochapecó, relativos à atuação do ESJ - Xaxim consigna os seguintes dados:

\begin{tabular}{|c|c|c|c|c|}
\hline Ano & Atendimentos & $\begin{array}{l}\text { Petições iniciais } \\
\text { protocoladas }\end{array}$ & $\begin{array}{c}\text { Petições } \\
\text { intermediárias } \\
\text { protocoladas }\end{array}$ & Áreas de atuação \\
\hline 2003 & 175 & - & - & $\begin{array}{l}\text { Civil, penal, trabalhista, } \\
\text { previdenciária }\end{array}$ \\
\hline 2004 & 90 & 35 & - & $\begin{array}{l}\text { Civil, penal, trabalhista, } \\
\text { previdenciária }\end{array}$ \\
\hline 2005 & 425 & 134 & - & $\begin{array}{l}\text { Civil, penal, trabalhista, } \\
\text { previdenciária }\end{array}$ \\
\hline 2006 & 503 & 53 & 96 & $\begin{array}{l}\text { Civil, penal, trabalhista, } \\
\text { previdenciária }\end{array}$ \\
\hline 2007 & 383 & 55 & 99 & $\begin{array}{l}\text { Civil, penal, trabalhista, } \\
\text { previdenciária }\end{array}$ \\
\hline 2008 & 285 & 25 & 111 & $\begin{array}{l}\text { Civil, penal, trabalhista, } \\
\text { previdenciária }\end{array}$ \\
\hline 2009 & 378 & 50 & 114 & $\begin{array}{l}\text { Civil, penal, trabalhista, } \\
\text { previdenciária }\end{array}$ \\
\hline 2010 & 586 & 70 & 160 & $\begin{array}{l}\text { Civil, penal, trabalhista, } \\
\text { previdenciária }\end{array}$ \\
\hline 2011 & 432 & 31 & 142 & $\begin{array}{l}\text { Civil, penal, trabalhista, } \\
\text { previdenciária }\end{array}$ \\
\hline Total & 3.257 & 453 & 722 & $\begin{array}{c}\text { Civil, penal, trabalhista, } \\
\text { previdenciária }\end{array}$ \\
\hline
\end{tabular}

Quadro 1: Desempenho do Escritório Sócio-Jurídico - Xaxim na competência 2003 - 2011

Fonte: Dados obtidos em relatórios institucionais e fichas de atendimento do Escritório Sócio- Jurídico.

Registra-se que os dados da tabela acima são fidedignos no que tange ao número de atendimentos realizados nas diferentes competências anuais, envolvendo demandas de natureza cível, criminal, trabalhista e previdenciária. Entretanto, a pesquisa efetivada revelou contradição entre o critério referente aos lançamentos dos dados das ações iniciais e intermediárias dos referidos relatórios de extensão da Unochapecó e o critério do Tribunal de Justiça de Santa Catarina respectivamente às ações protocoladas em Juízo.

apenas constam os números dos atendimentos realizados, motivo pelo qual houve prejuízo no levantamento destes dados.

Extensio: R. Eletr. de Extensão, ISSN 1807-0221 Florianópolis, v. 11, n. 17, p. 51-66, 2014. 
Especifica-se que o sistema de registro do Tribunal de Justiça de Santa Catarina é formalizado em sequência de numeração, da qual constam os três primeiros dígitos referentes à Comarca (Xaxim - 081), seguido do ano em que houve ajuizamento da ação e, ao final, o número dos autos.

Constata-se que, no período de 2003 até 2011, o ESJ-Xaxim efetuou 3.257 atendimentos à população da Comarca de Xaxim, sendo que destes, foram ajuizadas 453 ações iniciais e, realizadas ainda 722 peças intermediárias, que podem representar desde o acompanhamento da demanda ajuizada, até a defesa ou recurso de ação judicial.

Portanto, o serviço prestado pela equipe de prática jurídica no ESJ-Xaxim no período de 2003 a 2011 propiciou à população o efetivo acesso ao sistema judiciário de cerca de $40 \%$ dos atendimentos efetuados ${ }^{6}$. Consigna-se aqui que o percentual ora apontado se restringe apenas ao acesso ao poder judiciário, ressalvados o significativo número de atendimentos e encaminhamentos extrajudiciais caracterizadores também do acesso mais amplo à justiça.

A seguir, ilustram-se por meio de gráficos e descrevem-se os dados compilados a partir da presente pesquisa, como forma de demonstrar o acesso ao sistema judiciário através do desempenho do Escritório Sócio-Jurídico de Xaxim no período compreendido dos anos 2003 a 2011.

\section{Atendimentos}

Os atendimentos no ESJ-Xaxim são efetuados por estudantes do Curso de Direito em fase de estágio curricular obrigatório, sob a supervisão de professores das áreas de atuação do serviço. Quando necessário e a depender da demanda contam com a participação de estudantes do curso de Serviço Social.

A seguir apresenta-se graficamente os atendimentos efetuados pelo ESJ-Xaxim no período de 2003 -2011:

\footnotetext{
5 Registra-se que os dados foram coletados nas fichas de atendimento, sendo levado em consideração apenas o nome da pessoa que inicialmente procurou o serviço, sendo que este dado poderá ser ampliado se a atuação do serviço atingir demais membros da família.

6 Explicita-se que a metodologia utilizada considerou os 3.257 atendimentos efetivados pelo ESJ-Xaxim, que implicaram no ajuizamento de 722 petições intermediárias e 453 peças iniciais. As ações ajuizadas e as petições intermediárias perfazem cerca de $40 \%$ dos 3.257 atendimentos/demandas.
} 


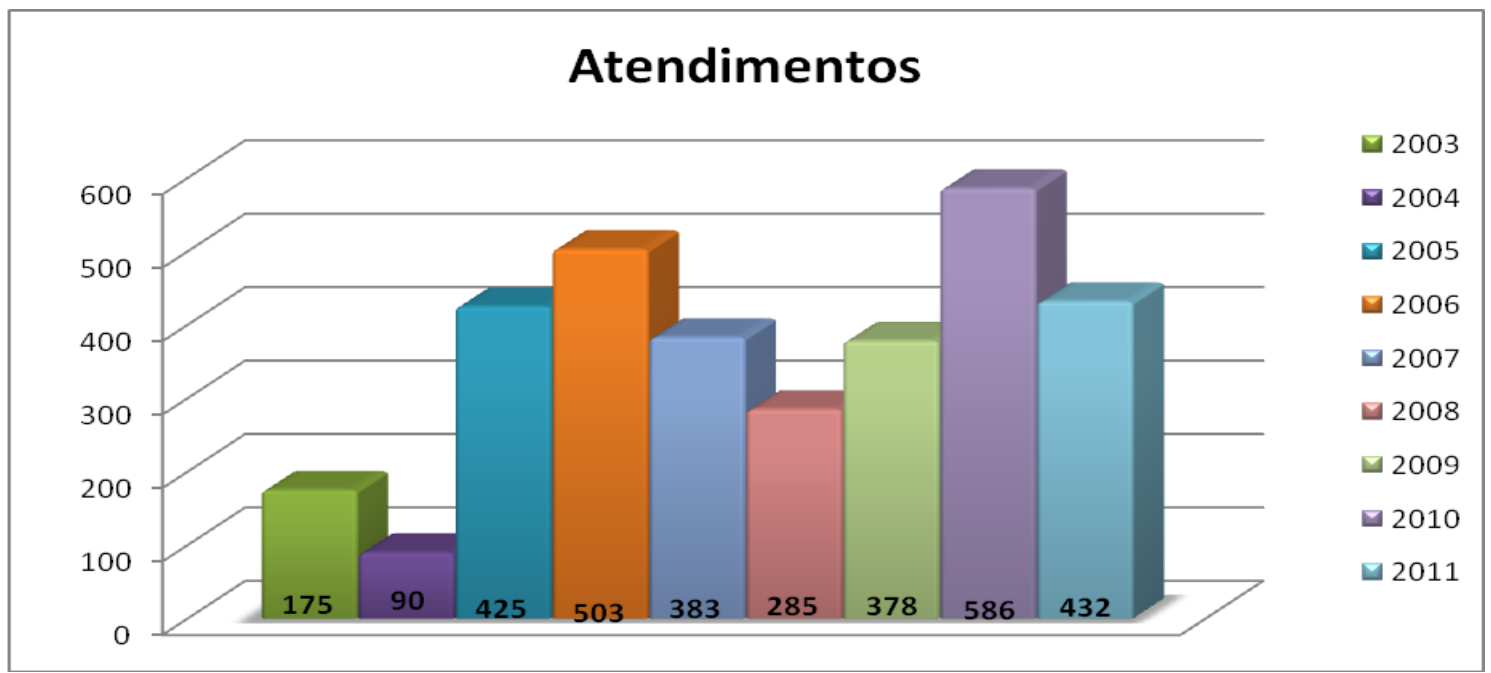

Gráfico 1: Atendimentos efetuados no período de 2003 a 2011 Fonte: Elaborado pelos autores.

A prática jurídica é materializada por meio do atendimento ao usuário/cliente do serviço, tanto a prestação de informações jurídico-sociais, quanto o encaminhamento a instituições e, também, o ajuizamento de ações junto ao Fórum de Justiça, como forma de defesa e garantia de direitos e o acesso à justiça.

\section{Petições iniciais ajuizadas}

No caso do atendimento efetuado pelo ESJ-Xaxim implicar na intervenção do Poder Judiciário, os estudantes formulam a peça processual que será submetida ao Juiz de Direito da Comarca para que, dentro das competências legais, resolva o conflito ou submeta a decisão das partes para homologação, julgando o processo por sentença.

O quadro subseqüente apresenta graficamente o rol de ações ajuizadas nas respectivas competências anuais, na Justiça Estadual da Comarca de Xaxim - SC: 


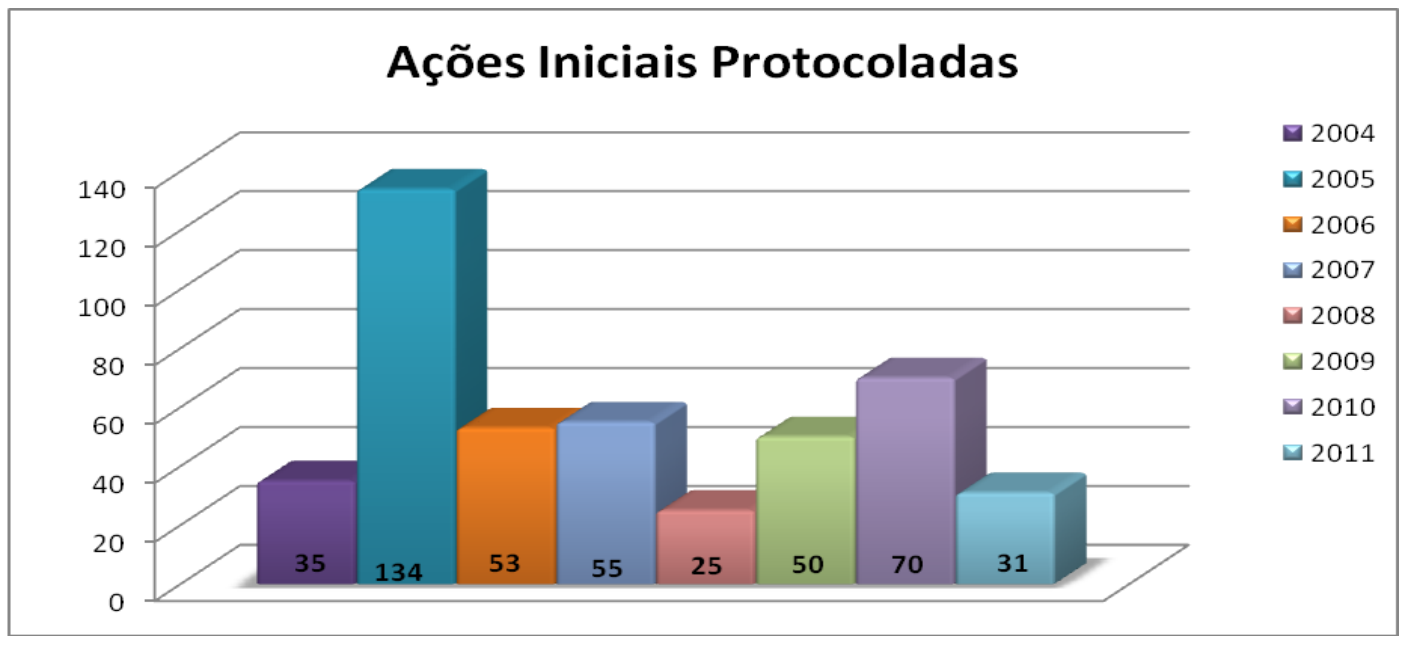

Gráfico 2: Ações iniciais protocoladas no período de 2004 à $2011^{7}$

Fonte: Elaborado pelos autores.

Do resultado das demandas judiciais, consigna-se que o alcance dos benefícios obtidos pelo cidadão atendido por meio do serviço prestado pelo ESJ-Xaxim, poderá atingir todo o grupo familiar, dependendo da controvérsia jurídica ou da ação ajuizada, a exemplo dos conflitos familiares (direito civil).

\section{Áreas de atuação jurídica e resultados das demandas ajuizadas}

No âmbito jurídico, o ESJ-Xaxim oferece para a população residente na Comarca de Xaxim serviços nas áreas de Direito Civil, Penal, Previdenciário e Trabalhista, proporcionando ao cidadão o acesso ao Poder Judiciário em vários campos de atuação, sob a forma de Assistência Jurídica Integral e Gratuita, de acordo com o previsto na Constituição Federal de 1988.

Neste sentido, a Tabela 2, demonstra as Áreas de atuação e resultados das ações ajuizadas pelo Escritório Sócio-Jurídico de Xaxim no período 2003-2011:

\begin{tabular}{|l|c|c|c|c|c|c|c|c|c|}
\hline Ano & Cível & Penal & $\begin{array}{l}\text { Traba } \\
\text { lhista }\end{array}$ & $\begin{array}{l}\text { Previden } \\
\text { ciária }\end{array}$ & $\begin{array}{l}\text { Sentenças } \\
\text { Procedentes }\end{array}$ & $\begin{array}{l}\text { Sentenças } \\
\text { Improce- } \\
\text { dentes }\end{array}$ & $\begin{array}{l}\text { Em } \\
\text { trâmi } \\
\text { tação }\end{array}$ & $\begin{array}{l}\text { Parcial } \\
\text { proce- } \\
\text { dente }\end{array}$ & $\begin{array}{l}\text { Arqui- } \\
\text { vado }\end{array}$ \\
\hline $2003^{8}$ & 18 & 02 & - & 01 & 17 & 04 & - & - & - \\
\hline
\end{tabular}

7 Não foram encontrados dados referentes a ações ajuizadas no ano de 2003.

8 Em apuração dos dados relativos às demandas ajuizadas pelo Escritório Sócio-jurídico na competência 2003 na Comarca de Xaxim, restou confirmado junto ao site do Tribunal de Justiça de Santa Catarina - TJ/SC que das ações ajuizadas no ano de 2003 encontrou-se 21 decisões referentes a demandas do ESJ - Xaxim.

Extensio: R. Eletr. de Extensão, ISSN 1807-0221 Florianópolis, v. 11, n. 17, p. 51-66, 2014. 


\begin{tabular}{|c|c|c|c|c|c|c|c|c|c|}
\hline 2004 & 19 & - & - & - & 15 & 04 & - & - & - \\
\hline 2005 & 34 & 02 & - & - & 27 & 05 & 02 & - & 02 \\
\hline 2006 & 16 & 02 & - & - & 10 & 04 & 04 & - & - \\
\hline 2007 & 17 & 02 & - & - & 11 & 06 & 01 & 01 & - \\
\hline 2008 & 11 & 01 & - & - & 07 & 03 & 01 & 01 & - \\
\hline 2009 & 11 & 03 & - & - & 07 & 04 & 03 & - & - \\
\hline 2010 & 15 & 01 & - & - & 06 & - & 09 & 01 & - \\
\hline 2011 & 19 & 01 & - & - & 11 & 01 & 08 & - & - \\
\hline Total & $\mathbf{1 6 0}$ & $\mathbf{1 4}$ & $\mathbf{0}$ & $\mathbf{0 1}$ & $\mathbf{1 1 1}$ & $\mathbf{3 1}$ & $\mathbf{2 8}$ & $\mathbf{0 3}$ & $\mathbf{0 2}$ \\
\hline
\end{tabular}

Quadro 2: Áreas de atuação e resultados das ações ajuizadas pelo Escritório Sócio-Jurídico Fonte: Dados obtidos junto ao site do TJ/SC.

Como resultado das demandas ajuizadas pelo ESJ-Xaxim, assinala-se como decisões as sentenças proferidas pelo Judiciário que foram procedentes ao pedido formulado na inicial, improcedentes ou parcialmente procedentes ao pleiteado através do Escritório Sócio-Jurídico. Consideraram-se também como resultados importantes para a pesquisa os processos que ainda estão em tramitação, portanto sem um resultado definitivo da ação protocolada no Fórum e os que foram arquivados administrativamente.

Analisando os dados computados na tabela acima se constata que das 175 ações ajuizadas, cerca de $92 \%$ correspondem a situações que envolvem o direito civil, seguida do direito penal e ainda praticamente inexiste procura da população pelos serviços jurídicos do ESJ para a atuação na defesa e garantia de direitos nas áreas trabalhista e previdenciária.

Das ações iniciais protocoladas por intermédio do Escritório Sócio-Jurídico, representando interesses e defesa de direitos da população hipossuficiente residente na Comarca de Xaxim, junto ao Poder Judiciário no período de 2003-2011, registra-se que houve 111 sentenças judiciais procedentes e 03 sentenças parcialmente procedentes, obtendo-se como resultado favorável para os pleitos de aproximadamente $65 \%$, resultado este que poderá ser aumentado levando em consideração que existem 28 processos ainda em tramitação, ou seja, sem decisão judicial. E, cerca de $18 \%$ dos processos ajuizados foram julgados improcedentes. 
Como decorrência das informações da pesquisa verifica-se que o Escritório SócioJurídico da Unochapecó na Comarca de Xaxim, contribui de forma efetiva para que a população usuária tenha respeitado o acesso à justiça e ao sistema judiciário, por meio do oferecimento qualificado de serviços jurídicos, pelos estudantes em estágio curricular, desde o atendimento até a proposição, acompanhamento processual e decisão judicial da demanda ajuizada.

\section{CONSIDERAÇÕES FINAIS}

O Escritório Sócio-Jurídico de Xaxim, mantido pela Unochapecó constitui-se em um dos principais mecanismos de acesso à justiça, a partir do trabalho desenvolvido por estudantes dos cursos de Direito e Serviço Social, em estágio de prática-jurídico-social, orientados por professores regularmente credenciados, com atendimento extensivo à população carente aos municípios pertencentes à abrangência territorial e jurisdicional da Comarca de Xaxim, SC.

Pelos resultados levantados com a pesquisa observa-se que a maioria dos conflitos em que as pessoas buscam o atendimento envolve questões da área do Direito Civil e Processo Civil, sendo que, como resultado das demandas ajuizadas obteve-se um percentual de aproximadamente $65 \%$ de decisões favoráveis.

Percebe-se pelo exposto na pesquisa, que a atuação do Escritório Sócio-Jurídico na Comarca de Xaxim, com o atendimento às pessoas hipossuficientes, possibilita a esta parcela da população, que encontra-se desprovida de direitos básicos, inclusive de informações jurídico-sociais, o ingresso ao sistema do judiciário, como contribuição efetiva de acessar a justiça social.

Os desafios que se colocam para o Escritório Sócio-Jurídico e para a Unochapecó a partir das informações e resultados da presente pesquisa consistem na ampliação dos serviços para a população da Comarca de Xaxim, propiciando o reconhecimento e acessibilidade dos direitos dos cidadãos, com o intuito de aumentar os atendimentos e as demandas judiciais, notadamente nas áreas do Direito Penal, Trabalhista e Previdenciária. Além disto, a utilização de recursos de registros administrativos compatíveis com o sistema utilizado pelo Poder Judiciário facilitaria a constatação e precisão dos dados das demandas ajuizadas e dos respectivos resultados. 
Pela comprovação dos dados consignados nesta pesquisa, afirma-se que o serviço prestado pelo Escritório Sócio-Jurídico de Xaxim, espaço mantido pela Unochapecó e que objetiva proporcionar ao estudante o exercício da prática-jurídica junto à comunidade, serve não apenas para cumprir um critério pedagógico e curricular de formação profissional do estudante no curso de Direito, mas também e o mais importante, é um instrumento que oferece à população de baixa renda, a informação jurídica e o ingresso no Poder Judiciário com as garantias processuais, o que representa a concretização do direito de cidadania, do legítimo acesso aos direitos e da efetiva justiça social.

\section{REFERÊNCIAS}

ANDRIGUI, Fátima Nancy. As formas de acesso à justiça no Brasil. In: Curso de direito brasileiro para advogados argentinos, 1998, Buenos Aires. Anais.... Buenos Aires: Instituto de Estudos Brasileiros da Universidade San Martín, 1998. 13 p. Disponível em: < http://www.researchgate.net/publication/28766610_As_Formas_de_Acesso_Justia_no_Brasi 1>. Acesso em: 19 jun. 2012.

BRANDÃO, Raimundo dos Reis. O acesso à justiça como um direito fundamental. Disponível em: http://www.conpedi.org.br/manaus/arquivos/anais/campos/raimundo_dos_reis brandao.pdf $>$. Acesso em: 19 jun. 2012.

BRASIL. Constituição da República Federativa do Brasil.1988. Disponível em: < http://www.planalto.gov.br/ccivil_03/constituicao/constitui\%C3\%A7ao.htm>. Acesso em: 22 jun. 2012.

CAOVILlA, Maria Aparecida Lucca. Acesso à justiça e cidadania. 2. ed. rev. e ampl. Chapecó, SC: Argos, 2006.

CAPPELlETTI, Mauro e GARTH, Bryant. Acesso à justiça. Tradução Ellen Gracie Northfleet. Porto Alegre: 1988.

DALLARI, Dalmo de Abreu. Breve história dos direitos humanos. In: Educação, cidadania e direitos humanos. José Sérgio Carvalho (org.). Petrópolis, RJ: Vozes, 2004. 
Acesso à justiça popular: uma importante experiência prático-jurídica-social universitária

UNOCHAPECÓ. Inaugurado em Xaxim espaço para atendimento jurídico. Em: 01 jun. 2012. Disponível em: <http://www.unochapeco.edu.br/noticias/inaugurado-em-xaximespaco-para-atendimento-juridico-2 01/06/2012>. Acesso em: 02 jun. 2012.

WATANABE, Kazuo. Acesso à justiça e sociedade moderna. In: Participação e processo. Revista dos Tribunais: São Paulo, 1988. 